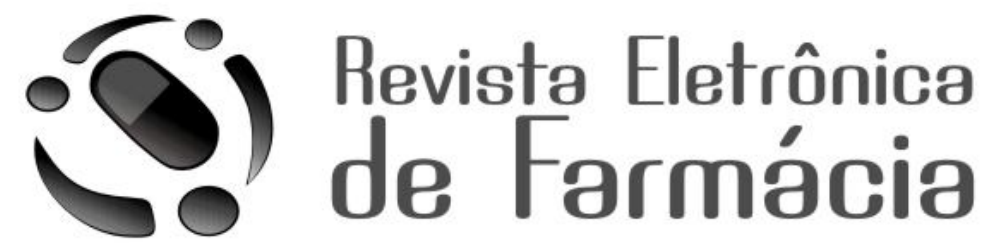

REF - ISSN 1808-0804 Vol. VIII (2), 71-82, 2011

\title{
TRIAGEM VIRTUAL INVERSA COMO FERRAMENTA PARA A Química de PRODUTOS NATURAIS
}

REVERSE VIRTUAL SCREENING AS A TOOL FOR THE CHEMISTRY OF NATURAL PRODUCTS

\author{
${ }^{1}$ Ana Paula Carregal, ${ }^{2}$ Alex Gutterres Taranto, ${ }^{3}$ Moacyr - Comar, ${ }^{4}$ Luciana Alves Lima, ${ }^{5}$ oão \\ Máximo de Siqueira \\ ${ }^{1}$ Universidade Federal de São João del-Rei, Farmácia \\ ${ }^{2}$ Universidade Federal de São J oão del-Rei, Química Farmacêutica \\ ${ }^{3}$ Universidade Federal de São João del-Rei, Físico-Química \\ ${ }^{4}$ Universidade Federal de São João del-Rei, Fitoquímica \\ ${ }^{5}$ Universidade Federal de São João del-Rei, Farmacognosia
}

Email da autora para correspondência: anapaulacarregal@gmail.com

Recebido em 23/ 07/ 2010, Aceito em 02/ 02/ 2011

\section{RESUMO}

A Triagem Virtual Inversa, ou Triagem Inversa, consiste em uma busca em banco de dados de estruturas protéicas, sendo estas de relevância farmacológica, de maneira a evidenciar in silico, os receptores farmacológicos de atuação para um determinado ligante de interesse. A plataforma utilizada denomina-se Sc-PDB, o qual é um software on-line que abriga somente alvos farmacológicos, sendo selecionadas a partir do PDB. O principal objetivo deste estudo é realizar o processo de TVI para neurotransmissores cujos receptores encontram-se descritos no PDB. Este estudo preliminar busca validar o método de TVI para uma posterior aplicação em compostos naturais. A estrutura dos 
Carregal, A. P., Taranto, A. G., Comar, M., Lima, L.A., Siqueira, J. M. / Revista Eletrônica de Farmácia Vol 8 (1), $71-82,2011$

neurotransmissores da adrenalina, serotonina e adenosina foram submetidos ao programa on-line SC-PDB. Onze variáveis foram estudadas, cada uma separadamente, mantendo as demais segundo o default do programa. Após esse procedimento foi estabelecido um protocolo, o qual será utilizado na busca de receptores de compostos naturais. Nesse protocolo ficou estabelecido o procedimento que encontra maior número de ligantes, na qual a molécula deve ser gerada sem os seus hidrogênios, sem estereoquímica, definindo como parâmetro de entrada subestrutura, e sem considerar variáveis como número de ligações rotáveis, de anéis ou de grupos doadores e receptores de ligação hidrogênio.

Palavras chaves: Desenvolvimento de fármacos, Modelagem Molecular, Bioinformática, TVI.

\section{ABSTRACT}

The Virtual Screening Reverse, or Reverse Screening consists of a search database of protein structures, which are of pharmacological relevance, in order to demonstrate in silico, the receptors of pharmacological activity for a particular ligand of interest. The platform used is called the Sc-PDB, which is online software that contain only pharmacological targets from PDB. The main objective of this study is apply the TVI methodology for neurotransmitters, which receptors are described in the PDB. This preliminary study validates this methodology for further use in natural compounds. The structure of the neurotransmitters epinephrine, serotonin and adenosine were submitted to the online program Sc-PDB. Eleven variables were studied separately according to the default of the program. As a result, a protocol was established to search receptors of natural compounds, which the ligand must be generated without its hydrogen, without stereochemistry definition, using substructure parameter, and without consider variables such as number of routable bonds, number of rings, and numbers of acceptor and donors of hydrogen bond groups.

Key word: Drug design, Molecular Modeling, Bioinformatics, IVS 
Carregal, A. P., Taranto, A. G., Comar, M., Lima, L.A., Siqueira, J. M. / Revista Eletrônica de Farmácia Vol 8 (1), 71 - 82, 2011

\section{N TRODUÇÃO}

Os produtos naturais despertam grande atenção pela sua variedade química e histórico de fármacos projetados a partir dessas fontes. Muitas destas moléculas naturais possuem atividade biológica, sendo consideradas como compostos protótipos. Estes fornecem uma estrutura inicial que após modificações estruturais aperfeiçoam as propriedades farmacológicas. Conseqüentemente, os compostos modificados podem originar um novo fármaco (BUTLER,2004). Várias plantas medicinais vêm sendo estudadas nos últimos anos e apesar de vários esforços pouco ainda se sabe quanto ao mecanismo de ação dos princípios ativos. Vários ensaios biológicos in vivo e in vitro são necessários para elucidar esta questão, acarretando um grande custo operacional.

Nos últimos anos, houve o surgimento de vários projetos genomas descrevendo vários receptores farmacológicos. Esses receptores, complexados com ligantes, são depositados no Protein
Data Bank (PDB). O PDB é o maior banco de dados de estruturas tridimensionais de proteínas obtidas experimentalmente, em sua maioria, por cristalografia de raios-X ou Ressonância Magnética Nuclear (RMN) (BERMAN et al, 2000). O banco de dados foi cuidadosamente construído, pesquisando bases de dados de diversas proteínas e armazenando, para cada entrada scAPO, as seguintes características: o nome da proteína, a função de origem, domínio e mutações, o nome do ligante, e estrutura. O sc-PDB pode ser utilizado para diversas finalidades: (i) selecionar uma coleção de sítios de ligação para prever o destino mais provável de qualquer ligante, (ii) analisar a semelhança molecular entre os sítios de ligação, e (iii) as regras decorrentes que descrevem a relação entre o ligante e pontos farmacológicos e propriedades do sítio ativo. O banco de dados é periodicamente atualizado e disponível na Internet (KELLENBERGER et al, 2006). 
Carregal, A. P., Taranto, A. G., Comar, M., Lima, L.A., Siqueira, J. M. / Revista Eletrônica de Farmácia Vol 8 (1), 71 - 82, 2011

Paralelamente,

quimioinformática,

sobretudo

a

a

metodologia de triagem virtual inversa (TVI), vem se desenvolvendo e sugerindo soluções rápidas e de baixo custo para questões químicas e biológicas. A Triagem Virtual Inversa, ou Triagem Inversa, consiste em uma busca em banco de dados de estruturas protéicas, sendo estas de relevância farmacológica, de maneira a evidenciar in silico, os receptores farmacológicos de atuação para um determinado ligante de interesse (ROGNAN, 2006). A plataforma utilizada denomina-se scPDB, o qual é um software on-line que abriga somente alvos farmacológicos, sendo selecionadas a partir do PDB. O sc-PDB realiza uma comparação por similaridade estrutural entre os ligantes complexados e a estrutura de interesse. A atual versão do SC-PDB, liberada em 2009, contém 7.070 entradas, das quais 2.378 e 3.687 são, respectivamente, proteínas e ligantes diferentes. Assim, com as informações contidas em cada entrada é possível realizar a triagem de uma molécula de interesse no sítio ativo de cada proteína do banco de dados (KELLENBERGER et al, 2006). Assim, o principal objetivo deste estudo é realizar o processo de TVI para neurotransmissores cujos receptores encontram-se descritos no PDB. Este estudo preliminar busca validar o método de TVI para uma posterior aplicação em compostos naturais.

\section{MATERIAL E MÉTODOS}

$$
\text { A estrutura }
$$

dos neurotransmissores adrenalina, serotonina e adenosina foram submetidos ao programa on-line scPDB. Onze variáveis foram estudadas, sendo elas presença ou não de hidrogênios, estereoquímica dos carbonos quirais (com ou sem estereoquímica definida), subestrutura, superestrutura, exata estrutura, exato fragmento, perfeita estrutura, número de ligações rotáveis, número de anéis, quantidade de grupos doadores, e receptores de ligação hidrogênio. Cada variável foi estudada separadamente, mantendo as demais segundo o default do programa. 
Carregal, A. P., Taranto, A. G., Comar, M., Lima, L.A., Siqueira, J. M. / Revista Eletrônica de Farmácia Vol 8 (1), 71 - 82, 2011

\section{RESULTADOS}

Os resultados obtidos da primeira variável indicaram que a presença de hidrogênios não interfere no número de receptores encontrados. Este resultado foi esperado uma vez que a grande maioria das estruturas depositadas no PDB, tanto ligante como macromoléculas, não possui os respectivos hidrogênios. Isto é devido ao método de obtenção empregado, cristalografia de raios- $X$ (BERMAN et al, 2006). estereoquímica. Como pode ser observado, as estruturas geradas sem estereoquímica encontram mais ligantes do que aquelas desenhadas com estereoquímica definida, o que já seria esperado pois o par de enantiômeros foi encontrado durante a busca. Este resultado sugere qual estereoquímica o ligante deve ter para que se ligue de forma mais efetiva ao receptor, direcionando assim o processo racional de desenvolvimento de fármacos.

A Tabela 1 apresenta os resultados obtidos para a

\begin{tabular}{|l|l|l|l|}
\hline Neurotransmissor & $\begin{array}{l}\text { Com } \\
\text { estereoquímica }\end{array}$ & $\begin{array}{l}\text { Sem } \\
\text { estereoquímica }\end{array}$ & $\begin{array}{l}\text { palavar } \\
\text { chaves }\end{array}$ \\
\hline Adenosina & 1519 ligantes & 1553 ligantes & 1064 \\
\hline Adrenalina & 1 ligante & 2 ligantes & 16 \\
\hline Serotonina & Não tem & 6 ligantes & 63877 \\
\hline
\end{tabular}

Tabela 1: Resultados obtidos da estereoquímica para neurotransmissores utilizados no estudo e da busca por palavras chaves do PDB.

Os resultados para os na Tabela 2. Dentre os cinco parâmetros de entrada disponíveis parâmetros de entrada analisados, a no programa sc-PDB são mostrados forma de subestrutura permitiu 
Carregal, A. P., Taranto, A. G., Comar, M., Lima, L.A., Siqueira, J. M. / Revista Eletrônica de Farmácia Vol 8 (1), 71 - 82, 2011

encontrar o maior número de serotonina o mesmo padrão se ligantes. Por outro lado, repete. Foram encontrados seis superestrutura não encontrou ligante para nenhum dos ligantes no parâmetro subestrutura, e nenhum ligante para os demais neurotransmissores. Exata estrutura, exato fragmento e perfeita estrutura encontraram aproximadamente o mesmo número de ligantes para cada neurotransmissor. Para a adenosina o parâmetro de entrada subestrutura encontrou 1524 ligantes a mais do que os parâmetros exata estrutura, exato fragmento e perfeita estrutura. Para o neurotransmissor parâmetros. Para a adrenalina, a busca encontrou dois ligantes para o parâmetro subestrutura e nenhum para superestrutura. Os parâmetros exata estrutura e exato fragmento encontraram um ligante cada um, porém perfeita estrutura, que deveria assim como exata estrutura e exato fragmento encontrar um ligante, não encontrou nenhum.

\begin{tabular}{|l|l|l|l|}
\hline $\begin{array}{l}\text { Tipo } \\
\text { pesquisa }\end{array}$ & Adenosina & Adrenalina & Serotonina \\
\hline Subestrutura & 1553 ligantes & 2 ligantes & 6 ligantes \\
\hline $\begin{array}{l}\text { Superestrutura } \\
\text { estrutura }\end{array}$ & 29 ligantes & 1 ligante & Não encontrou \\
\hline $\begin{array}{l}\text { Exato } \\
\text { fragmento }\end{array}$ & 29 ligantes & 1 ligante & Não encontrou \\
\hline $\begin{array}{l}\text { Perfeita } \\
\text { estrutura }\end{array}$ & 29 ligantes & Não encontrou & Não encontrou \\
\hline
\end{tabular}

Tabela 2: Resultados obtidos para os diferentes parâmetros de entrada apresentados pelo sc-PDB.

Os resultados obtidos para os rotáveis, número de anéis, parâmetros número de ligações quantidade de grupos doadores, e 
Carregal, A. P., Taranto, A. G., Comar, M., Lima, L.A., Siqueira, J. M. / Revista Eletrônica de Farmácia Vol 8 (1), 71 - 82, 2011

receptores de ligação hidrogênio são mostrados na Tabela 3. De uma forma geral tais parâmetros diminuem o número de ligantes encontrados, sugerindo que a melhor opção é mantida pelo default. De acordo com a tabela a adenosina encontrou no default 1095 ligantes a mais do que quando o número de ligações rotáveis foi limitado e 691 a mais do que quando quantidade de anéis foi limitada. O número de grupos doadores e receptores de ligações hidrogênio afeta consideravelmente a quantidade de ligantes encontrados. Como pode ser observado na Tabela 3 quando a quantidade de grupos doadores de hidrogênio foi maior ou igual a quatro a pesquisa encontrou 834 ligantes a mais para a adenosina do que quando a quantidade foi igual a quatro. De modo semelhante quando quantidade de grupos receptores foi igual a nove a pesquisa não encontrou ligante, porém quando a quantidade foi maior ou igual a nove o número de ligantes encontrados foi igual a 1521. Para a serotonina o padrão da adenosina se repete. No default a pesquisa encontrou cinco ligantes a mais do que quando o número de ligações rotáveis e de anéis foi limitado. Não foram encontrados ligantes para a serotonina quando a quantidade de grupos doadores e receptores de hidrogênio foi igual a três. Porém quando a quantidade de grupos doadores e receptores foi maior ou igual e três a pesquisa encontrou dois e cinco ligantes respectivamente. Para a adrenalina, o mesmo resultado se repetiu no default e quando o número de ligações rotáveis foi limitado. Para os demais parâmetros o número de ligantes encontrados foi igual a um. A metodologia TVI também foi comparada com a busca por palavras chaves do PDB para os três neurotransmissores, onde os resultados estão apresentados na Tabela 3. Como pode ser observado, a busca por palavras chaves encontrou um número maior de ligantes para adrenalina e serotonina, enquanto houve um decréscimo para a adenosina. O método TVI associado ao Sc-PDB foi 
Carregal, A. P., Taranto, A. G., Comar, M., Lima, L.A., Siqueira, J. M. / Revista Eletrônica de Farmácia Vol 8 (1), 71 - 82, 2011

capaz de encontrar 489 ligantes a

mais do que a busca por palavras

chaves para adenosina. Por outro

lado, esse padrão não foi observado

para a adrenalina e serotonina. A

busca por palavras encontrou 14 e

63871 de ligantes a mais para a

adrenalina e para serotonina,

respectivamente do que a busca pelo
SC-PDB. No entanto, o método TVI associado ao sc-PDB foi capaz de encontrar um receptor para a adrenalina no PDB, a qual não foi observado na busca por palavras chaves. Em outras palavras, o método TVI mostra-se mais eficiente na busca de ligantes.

\begin{tabular}{|c|c|c|c|c|c|c|c|}
\hline \multicolumn{8}{|c|}{ Adenosina } \\
\hline & default & $\begin{array}{l}\text { Número de } \\
\text { ligações } \\
\text { rotáveis }\end{array}$ & $\begin{array}{l}\text { Número de } \\
\text { anéis }\end{array}$ & $\begin{array}{l}\text { Grupos } \\
\text { doadores de } \\
\text { ligação } \\
\text { hidrogênio }\end{array}$ & $\begin{array}{l}\text { Grupos } \\
\text { doadores de } \\
\text { ligação } \\
\text { hidrogênio }\end{array}$ & $\begin{array}{l}\text { Grupos } \\
\text { receptores de } \\
\text { ligação } \\
\text { hidrogênio }\end{array}$ & $\begin{array}{l}\text { Grupos } \\
\text { receptores de } \\
\text { ligação } \\
\text { hidrogênio }\end{array}$ \\
\hline & & $(>=1<=6)$ & $(>=1<=3)$ & $(=4)$ & $(>=4)$ & $(=9)$ & $(>=9)$ \\
\hline Subestrutura & $1553(1519)$ & $458(450)$ & $882(864)$ & $662(651)$ & $1496(1464)$ & N.O (3) & $1521(1493)$ \\
\hline Superestrutura & N.O & N.O & $\mathrm{N} . \mathrm{O}$ & N.O & $\mathrm{N} . \mathrm{O}$ & N.O & N.O \\
\hline Exata estrutura & $29(24)$ & $29(24)$ & $29(24)$ & $29(24)$ & $29(24)$ & $29(24)$ & $29(24)$ \\
\hline Exato fragmento & $29(24)$ & $29(24)$ & $29(24)$ & $29(24)$ & $29(24)$ & N.O & $\mathrm{N} . \mathrm{O}$ \\
\hline $\begin{array}{l}\text { Perfeita } \\
\text { estrutura }\end{array}$ & $29(24)$ & $29(24)$ & $29(24)$ & $29(24)$ & $29(24)$ & N.O & N.O \\
\hline \multicolumn{8}{|c|}{ Adrenalina } \\
\hline & & $(>=1<=7)$ & - & $(=4)$ & $(>=4)$ & $(=4)$ & $(>=4)$ \\
\hline Subestrutura & $2(1)$ & $2(1)$ & - & $1(1)$ & $1(1)$ & $1(\mathrm{~N} . \mathrm{O})$ & $1(\mathrm{~N} . \mathrm{O})$ \\
\hline Superestrutura & N.O & N.O & - & N.O & N.O & N.O & N.O \\
\hline Exata estrutura & $1(1)$ & $1(1)$ & - & $1(1)$ & $1(1)$ & $1(1)$ & $1(1)$ \\
\hline Exato fragmento & $1(1)$ & $1(1)$ & - & $1(1)$ & N.O & N.O & $1(\mathrm{~N} . \mathrm{O})$ \\
\hline $\begin{array}{l}\text { Perfeita } \\
\text { estrutura }\end{array}$ & N.O & N.O & - & N.O & N.O & N.O & N.O \\
\hline \multicolumn{8}{|c|}{ Serotonina } \\
\hline & & $(>=1<=4)$ & $(>=1<=2)$ & $(=3)$ & $(>=3)$ & $(=3)$ & $(>=3)$ \\
\hline Subestrutura & 6 & 1 & 1 & N.O & 2 & N.O & 5 \\
\hline Superestrutura & N.O & N.O & N.O & N.O & N.O & N.O & N.O \\
\hline Exata estrutura & N.O & N.O & N.O & N.O & N.O & N.O & N.O \\
\hline Exato fragmento & $\mathrm{N} . \mathrm{O}$ & N.O & N.O & $\mathrm{N} . \mathrm{O}$ & $\mathrm{N} . \mathrm{O}$ & $\mathrm{N} . \mathrm{O}$ & N.O \\
\hline $\begin{array}{l}\text { Perfeita } \\
\text { estrutura }\end{array}$ & N.O & N.O & N.O & N.O & N.O & N.O & N.O \\
\hline
\end{tabular}

Tabela 3: Resultados obtidos para número de ligações rotáveis, número de anéis, quantidade de grupos doadores, e receptores de ligação hidrogênio. Os resultados são da busca sem estereoquímica. Entre parênteses está o número de ligantes encontrados pela busca TVI com estereoquímica.

N.O: Não observado

A Figura 1 mostra apenas alguns exemplos de ligantes encontrados pelos neurotransmissores com os códigos PDB dos respectivos receptores. Como pode ser observado, os compostos 1 e 2,3 e 4, e 5-7 são estruturalmente semelhante à adenosina, adrenalina 
Carregal, A. P., Taranto, A. G., Comar, M., Lima, L.A., Siqueira, J. M. / Revista Eletrônica de Farmácia Vol 8 (1), $71-82,2011$

e serotonina, respectivamente. Os da adrenalina, para os compostos 3 e compostos 1 e 2, além da base 4. Os compostos 5,6 e 7 , nitrogenada e da ribose presentes na apresentam o grupamento indólico, adenosina, possuem os radicais principal grupo da serotonina. A fosfatos importantes para a presença dos grupamentos funcionais atividade biológica destes e farmacofóricos nos ligantes compostos. Semelhantemente, foi mostram o quanto o método é observado a presença do grupo eficiente para encontrar o alvo catecol, grupamento farmacofórico molecular de moléculas bioativas.
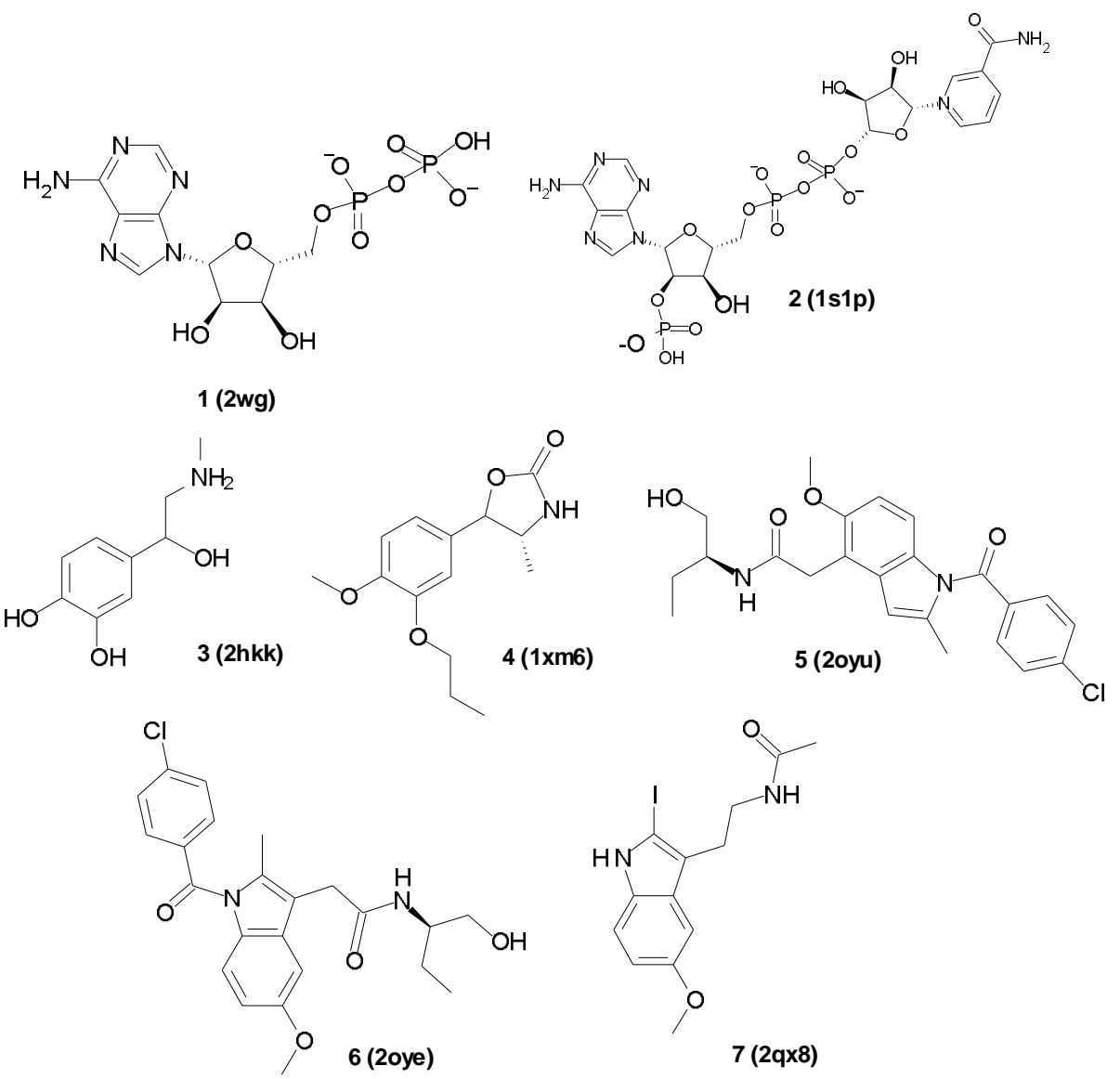

Figura 1: Exemplos de ligantes encontrados pelo método TVI usando adenosina ( 1 e 2), adrenalina ( 3 e 4), e serotonina (5-7). Entre parênteses encontra-se o código PDB do respectivo receptor. 
Carregal, A. P., Taranto, A. G., Comar, M., Lima, L.A., Siqueira, J. M. / Revista Eletrônica de Farmácia Vol 8 (1), 71 - 82, 2011

\section{SCUSSÃO}

Após esse procedimento foi estabelecido um protocolo, o qual será utilizado na busca de receptores de compostos naturais. Nesse protocolo ficou estabelecido o procedimento que encontra maior número de ligantes, na qual a molécula deve ser gerada sem os seus hidrogênios, sem estereoquímica, definindo como parâmetro de entrada subestrutura, e sem considerar variáveis como número de ligações rotáveis, de anéis ou de grupos doadores e receptores de ligação hidrogênio. O método é sensível o suficiente para distinguir entre estereoisômeros, sendo este parâmetro útil para refinar a busca.

A recente metodologia de triagem virtual inversa faz parte de um conjunto de metodologias de desenvolvimento racional de fármacos (ou compostos bioativos) (BARREIRO \& FRAGA, 2008). Estas metodologias permitem a criação de novos fármacos com base no conhecimento dos seus alvos biológicos. Esse processo envolve o desenho de pequenas moléculas complementares ao sítio ativo, a qual propicia a interação destas com o respectivo destino biomolecular. Existem dois tipos de metodologias para o desenho racional de moléculas bioativas. A primeira é definida como desenho de fármacos baseados no ligante (ligand-based drug design) e a segunda, desenho de fármacos baseado na estrutura do receptor (structure-based drug design). A primeira metodologia baseia-se no ligante para a investigação de outras moléculas que podem se ligar ao alvo biológico de interesse. Um modelo do alvo biológico pode ser construído com base no conhecimento da estrutura dos ligantes, permitindo projetar novas moléculas que se liguem a este modelo. A segunda metodologia usa a estrutura do alvo biológico para construir um mapa farmacofórico. Este método permite construir moléculas de ligantes dentro do sítio de ligação, facilitando o desenho de novas entidades terapêuticas (HÖLTJE, 2003). Assim, o processo de 
Carregal, A. P., Taranto, A. G., Comar, M., Lima, L.A., Siqueira, J. M. / Revista Eletrônica de Farmácia Vol 8 (1), $71-82,2011$

\begin{abstract}
desenvolvimento de fármacos pela metodologia TVI inicia-se com apenas uma estrutura de ligante, e segue uma ou várias estruturas de alvos biológicos. Como resultado, ambas as metodologias de desenho de fármacos podem ser empregadas, tendo essa como a principal vantagem desta metodologia. Esta pode ser ainda mais refinada se houver dados etnofarmacológicos (caso os ligantes sejam compostos naturais) direcionando ainda mais o processo de desenvolvimento.
\end{abstract}

\section{CONCLUSÃO}

De posse deste protocolo estabelecido, os estudos seguirão

\begin{abstract}
para encontrar potenciais alvos biológicos para compostos obtidos de fontes naturais. Em uma etapa posterior, a metodologia de ancoragem molecular será utilizada para sugerir modificações estruturais com objetivo de gerar compostos protótipos que podem se ligar mais fortemente ao receptor, projetando novos candidatos a fármacos.
\end{abstract}

\section{AGRADECI MENTOS}

A. P. Carregal agradece a bolsa PIBIC/CNPq/UFSJ obtida pelo edital 2010/2011. Os autores agradecem também ao CNPq $(475512 / 2010-3) \quad$ e $\quad$ a FAPEMIG (APQ-01855-10) pelo suporte financeiro.

\section{REFERÊNCI AS BI BLIOGRÁFI CAS}

BARREIRO EJ, FRAGA CAM. Química Medicinal: as bases moleculares da ação dos fármacos. Porto Alegre: Artmed, 2008.

BERMAN HM, WESTBROOK J, FENG Z, GILLILAND G, BHAT TN, WEISSIG H, et al. The protein data bank. Nucleic Acids Res. Out 2000; 28 (1): 235-242.

BUTLER MS. The role of natural product chemistry in drug discovery. J. Nat. Prod. 2004; 67:2141-2153. 
Carregal, A. P., Taranto, A. G., Comar, M., Lima, L.A., Siqueira, J. M. / Revista Eletrônica de Farmácia Vol 8 (1), $71-82,2011$

HÖLTJE H-D, SIPPL W, ROGNAN D, FOLKERS G. Molecular Modeling: Basic Principles and Applications. Weinheim: Wiley-VCH, 2003.

Kellenberger E， MULler P，SChAlON C，BRET G，FOATA N， ROGNAN D. SCPDB: an Annotated Database of Druggable Binding Sites from the Protein Data Bank. J. Chem. Inf. Model. Set 2006; 46: 717-727.

ROGNAN D. Development and virtual screening of target libraries. J. Physiol. $2006 ; 99: 232-244$. 